\title{
Identificação dos principais indicadores de sustentabilidade da caprinocultura leiteira: uma proposta de framework
}

A caprinovinocultura leiteira o Nordeste representa grande importância socioeconômica para esta região, em especial paro o Estado da Paraíba, sendo o maior produtor de leite caprino do país, com destaque para a microrregião do Cariri Ocidental paraibano. Diante da importância desta atividade econômica, justifica-se propor um sistema de indicadores de sustentabilidade. Desse modo, esta pesquisa tem-se objetivo elaborar uma matriz de indicadores de sustentabilidade caprinovinocultura leiteira, fruto disso, criou-se um modelo de avaliação de sustentabilidade em que se percebeu a necessidade de contemplar a temática capital social incluindo um novo atributo no método MESMIS - Marco para Avaliação de Sistemas de Manejo incorporando Indicadores de Sustentabilidade. Trata-se de uma pesquisa exploratória e descritiva em foi necessário realizar pesquisa de campo através de visitas in loco nas propriedades rurais, acompanhadas de entrevistas semiestruturadas e participação dos caprinovinocultores. Como resultado, foi proposto de inclusão do atributo capital social na metodologia MESMIS e elaborado um conjunto de indicadores em que originou um framework para avaliação da sustentabilidade da caprinocultura leiteira. Por fim, ao verificar a realidade da agricultura familiar na produção de leite caprino, percebeu-se que existe uma lacuna na metodologia MESMIS por não dar a ênfase nas relações sociais entre os produtores, mas apenas aos aspectos relacionados ao meio ambiente e produtividade. Desta forma, foi proposta uma adaptação do método MESMIS com a inclusão do atributo capital social a fim de tornar os resultados mais fidedignos e consistentes para a realidade da sustentabilidade da caprinocultura leiteira.

Palavras-chave: Indicadores de sustentabilidade; Caprinocultura leiteira; MESMIS; Capital Social.

\section{Dentification of the main sustainability indicators of dairy caprinoculture: a framework proposal}

\begin{abstract}
Goat dairy farming in the Northeast represents great socioeconomic importance for this region, especially for the State of Paraíba, being the largest goat milk producer in the country, with emphasis on the Cariri Western region of Paraíba. In view of the importance of this economic activity, it is justified to propose a system of sustainability indicators. Thus, this research aims to identify the main sustainability indicators for dairy goat farming in the municipalities of western Paraíba, as a result of this, a sustainability assessment model was created in which the need to contemplate the social capital theme was realized, including a new attribute in the MESMIS method - Framework for Assessment of Management Systems incorporating Sustainability Indicators. This is an exploratory and descriptive research in which it was necessary to conduct field research through on-site visits to rural properties, accompanied by semi-structured interviews and the participation of caprinovinoculturists. As a result, it was proposed to include the social capital attribute in the MESMIS methodology and a set of indicators was created in which it originated a framework for assessing the sustainability of dairy goats. Finally, when verifying the reality of family farming in the production of goat milk, it was noticed that there is a gap in the MESMIS methodology as it does not emphasize social relations between producers, but only aspects related to the environment and productivity. Thus, an adaptation of the MESMIS method was proposed with the inclusion of the social capital attribute in order to make the results more reliable and consistent for the reality of the sustainability of dairy goats.
\end{abstract}

Keywords: Sustainability indicators; Dairy goat; MESMIS; Social capital.

Topic: Sistemas de Gestão Ambiental

Reviewed anonymously in the process of blind peer.
Received: 03/04/2021

Approved: 26/04/2021
Robson Fernandes Barbosa (iD

Universidade Federal de Campina Grande, Brasil

http://lattes.cnpq.br/5329317234568143

http://orcid.org/0000-0002-8617-7215

robson_rfb@yahoo.com.br

José Otávio Aguiar (iD

Universidade Federal de Campina Grande, Brasil

http://lattes.cnpq.br/7106694267459903

http://orcid.org/0000-0003-0489-3670

otavio.j.aguiar@gmail.com

Stefane Nogueira Alexandre

Universidade Federal de Campina Grande, Brasil

http://lattes.cnpq.br/7843315090347789

http://orcid.org/0000-0003-3260-9999

stefanenogueira38@gmail.com

\author{
Mara Karinne Lopes Veriato Barros (iD \\ Universidade Federal de Campina Grande, Brasil \\ http://lattes.cnpq.br/9198696436575198 \\ http://orcid.org/0000-0003-1215-9599 \\ karinnelv@yahoo.com.br \\ Helder Morais Mendes Barros (D) \\ Universidade Federal de Campina Grande, Brasil \\ http://lattes.cnpq.br/7955183658651586 \\ http://orcid.org/0000-0001-8950-3023 \\ hmmbbr@yahoo.com.br
}

Referencing this:

BARBOSA, R. F.; AGUIAR, J. O.; ALEXANDRE, S. N.; BARROS, M. K. L. V.; BARROS, H. M. M.. Identificação dos principais indicadores de sustentabilidade da caprinocultura leiteira: uma proposta de framework. Revista Ibero Americana de Ciências Ambientais, v.12 n.4, p.783-795, 2021. DOI: http://doi.org/10.6008/CBPC21796858.2021 .004 .0059 


\section{INTRODUÇÃO}

A produção de leite, típica do Nordeste, é uma das atividades de maior contribuição para a economia dos estados desta região. Proveniente desta atividade, a produção de seus derivados também tem sido algo bastante praticado e comercializado (OLIVEIRA, 2020).

A cadeia produtiva da caprinocultura se constitui da produção do leite, carne e pele. Mas, que segundo Andrade (2007) apresenta limitação na comercialização da carne e pele por não ter uma cadeia produtiva organizada. Segundo ele, o abate clandestino é o maior gargalo na produção de carne e a existência de poucos curtumes e estes com produção artesanal interferem no beneficiamento da pele. Assim, encontram-se na produção, processamento e beneficiamento de leite uma cadeia produtiva mais organizada, esta análise foi preponderante para o direcionamento do foco desta pesquisa para o segmento da caprinocultura de leite na Paraíba.

Dessa forma, a produção e comercialização do leite de cabra proporcionou uma melhoria na renda do agricultor familiar, se tornado uma das principais atividades produtivas de fixação do homem do campo, evitando assim, o êxodo rural e seus impactos negativos, como por exemplo, vulnerabilidade social nos grandes centros urbanos.

A partir disso, torna-se relevante à existência de instrumentos para simplificar, quantificar e analisar informações perante a medição do progresso sob a ótica da sustentabilidade. Desse modo, tem-se a metodologia MESMIS como instrumento para avaliar a sustentabilidade sistemas de produção agrícola, florestal e/ou pecuária.

De acordo com Masera et al. (1999), os criadores do método MEMIS, definem como uma ferramenta que colabora na avaliação da sustentabilidade de manejo de recursos naturais, com ênfase no contexto da agricultura familiar e no âmbito local, buscando entender os fatores limitantes e as possibilidades para a sustentabilidade dos sistemas de manejo que surgem da interseção de processos ambientais com o âmbito social e econômico.

Portanto, o método MESMIS por mais que seja flexível, necessita de adaptação ou restruturação na sua concepção, pois necessita suprir sua deficiência na esfera social, pois ao se tratar de associações de caprinocultores de leite ou qualquer outro tipo de associação ou cooperativa não se pode tratar de forma secundária a dimensão humana e suas relações sociais. De maneira geral existe certa negligência no aspecto social em que as relações entre indivíduos não são consideradas em detrimento a aspectos que versa sobre produtividade e a temática ambiental.

Como proposta metodológica propõe-se dar ênfase a temática sobre capital social para suprir essa lacuna existente. Segundo Coleman (1988), o capital social de uma associação, grupo ou comunidade amplia sua capacidade de ação coletiva e facilita a cooperação mútua necessária para a otimização do uso de recursos materiais e humanos disponíveis. Para ele, "um grupo dentro do qual existe grande fidelidade e confiança está hábil a realizar muito mais do que um grupo comparável sem fidelidade e confiança".

Diante disto, o atributo capital social tem um peso decisivamente positivo para o sucesso de 
experiências de desenvolvimento (PUTNAM, 2002; BECATTINI, 2002). Para Masera et al. (1999) esclarece que não existe um conjunto de indicadores que se adeque a todos os agroecossistemas e sendo assim, suas adaptações e melhorias contínuas se fazendo necessário.

Assim, como objetivo propõe-se elaborar uma matriz de indicadores de sustentabilidade da caprinovinocultura leiteira dos municípios do cariri ocidental paraibano por meio da inclusão do capital social no método MESMIS e a partir dele criar um framework com a finalidade de aprimorar a metodologia e trazer resultados mais consistentes e fidedignos.

\section{METODOLOGIA}

\section{Caracterização da pesquisa}

A referida pesquisa enquadra-se quanto à natureza de uma pesquisa aplicada, objetivando solucionar de forma prática a problemática de propor um modelo de avaliação de sustentabilidade da caprinocultura leiteira. Assim, a pesquisa aplicada corresponde pela necessidade de busca de resolução de problemas de ordem concreta (VERGARA, 2007).

Quanto aos fins, é classificada como uma pesquisa descritiva e exploratória. Quanto aos meios, a pesquisa pode ser classificada como bibliográfica, de campo e participante, técnicas necessárias para atingir a finalidade da pesquisa.

A ferramenta metodológica utilizada nessa experiência de monitoramento da sustentabilidade é denominada: Marco para la Evaluación de Sistemas de Manejo de Recursos Naturales incorporando Indicadores de Sustentabilidade - MESMIS, (MASERA et al., 1999). Sendo uma metodologia participativa que objetiva avaliar a sustentabilidade dos sistemas de manejo produtivo, nos agroecossistemas em transição agroecológica, levando em consideração os aspectos ecológicos, sociais e econômicos, valorizando o fator do campesino.

Da mesma forma, Verona (2010) caracteriza o MESMIS como um processo dinâmico, interdisciplinar e multiprofissional, aberto a adaptações, onde as ações são reelaboradas e desenvolvidas em consonância com as necessidades dos agroecossistemas avaliados, sendo essencial a participação ativa dos pesquisadores, extensionistas e agricultores.

\section{População e amostra}

Delimita-se enquanto espaço de desenvolvimento da pesquisa o Cariri Ocidental paraibano, por apresentar a maior produção de leite caprino do país, maior quantidade de criadores, rebanho e pujança econômica oriunda caprinovinocultura leiteira do Estado. Na Figura 3, pode-se observar a diferença do tamanho territorial e a quantidades de cidades presentes entre as microrregiões do Cariri Ocidental e Oriental do Estado da Paraíba.

O cariri paraibano se divide em entre as microrregiões do Cariri Ocidental e Oriental, totalizando 29 municípios. No Cariri Ocidental são 17 (dezessete) municípios: Amparo, Assunção, Camalaú, Congo, Coxixola, 
Livramento, Monteiro, Ouro Velho, Parari, Prata, São João do Tigre, São José dos Cordeiros, São Sebastião do Umbuzeiro, Serra Branca, Sumé, Taperoá e Zabelê. Já no Cariri Oriental, dispõe de 12 (doze) municípios: Alcantil, Barra de São Miguel, Barra de Santana, Boqueirão, Cabaceiras, Caraúbas, Caturité, Gurjão, Riacho de Santo Antônio, Santo André, São Domingos do Cariri, São João do Cariri.

Neste sentido, o estudo limitou-se ao Cariri Ocidental da Paraíba pelos motivos supracitados em que houve uma estratificação dos municípios em quatro classes diferentes, levando em consideração a quantidade de leite de cabra produzida ano de 2017. Diante disso, foram selecionados os quatro municípios mais representativos de cada classe para representar o nível de sustentabilidade da caprinocultura leiteira dessa Microrregião. Ver Figura 2.

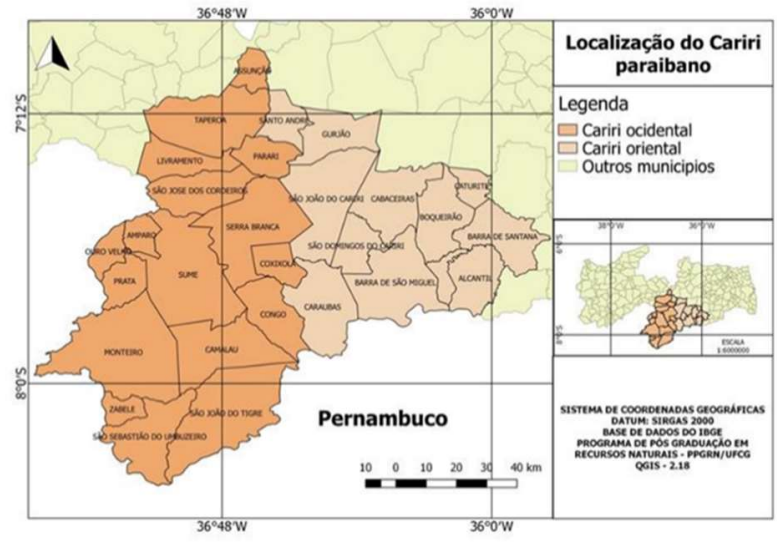

Figura 1: Mapa do Cariri paraibano.

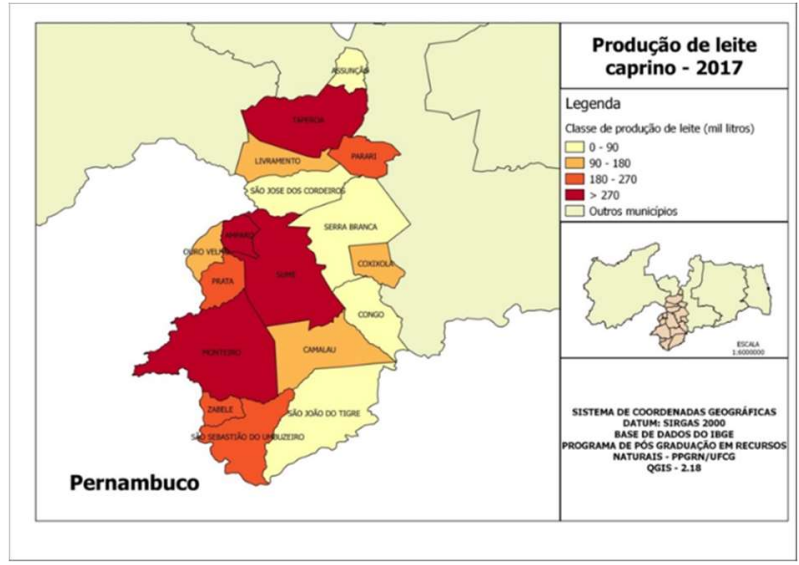

Figura 2: Mapa de classificação da produção de leite Caprino no Cariri Ocidental - 2017.

Como pode se observar, os munícipios foram divididos em 04 (quatro) classes de intervalos de acordo com a quantidade de litros de leite produzidos, representada com suas respectivas cores. Assim, como forma de simplificação esse estudo buscou enfatizar os municípios mais representativos em cada classe a fim de sintetizar uma visão geral do Cariri Ocidental. São eles em ordem crescente: São José dos Cordeiros, Coxixola, Parari e Monteiro.

\section{A Metodologia MESMIS}

O MESMIS (Marco para Avaliação de Sistemas de Manejo de Recursos Naturais Incorporando Indicadores de Sustentabilidade) pode ser considerado como um a ferramenta de gestão capaz de auxiliar famílias agricultoras na tomada de decisões sustentáveis. Trata-se de uma metodologia criada em 1995 no México pelo Grupo Interdisciplinar de Tecnologia Rural Apropriada (GIRA).

O MESMIS é orientado pelas seguintes premissas, onde o conceito de sustentabilidade é definido a partir de cinco atributos gerais, tais como: produtividade; estabilidade, confiabilidade e resiliência; adaptabilidade; equidade e; autogestão. Os atributos podem são detalhados a seguir, segundo Masera et al. (1999). Ver Figura 3. 


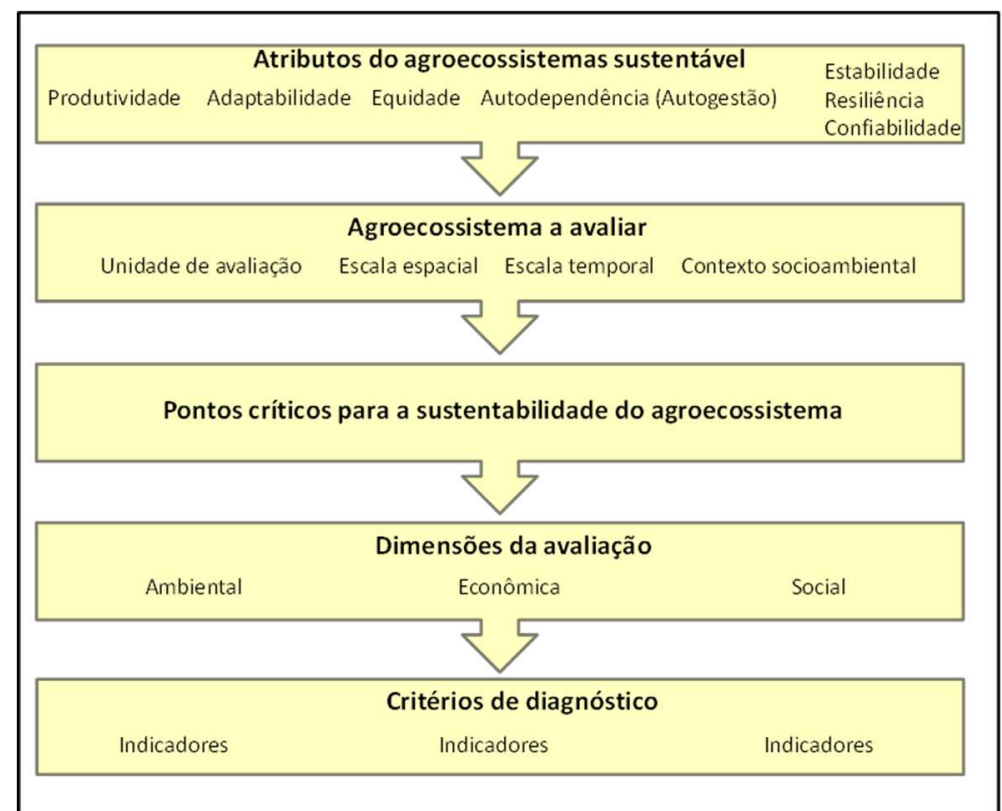

Figura 3: Estrutura do Método MESMIS - relação atributos, dimensões e indicadores de sustentabilidade. Fonte: Adaptado de Masera et al. (1999).

A seguir, os atributos do agroecossistema, em outras palavras o método MESMIS pode ser aplicado em qualquer propriedade agropecuária/florestal, a seguir: - Produtividade: são os rendimentos e ganhos da propriedade agropecuária/florestal. Trata-se da quantitativo de recursos que são necessários a fim de se obter determinado volume de produção levando em consideração o fator tempo; - Adaptabilidade: referese a capacidade da propriedade agropecuária/florestal encontrar novos níveis de equilíbrio. É a capacidade de buscar novas estratégias de produção de acordo com a demanda imposta. Inclui desde o desenvolvimento de novas tecnologias para melhorar a situação atual até a formação de recursos humanos e de aprendizagem; - Equidade: é divisão justa sobre os ganhos e perdas resultantes do manejo dos recursos naturais. É a capacidade de distribuir de forma equitativamente os prós e contras de determinado resultado para todos os responsáveis; - Autodependência ou autogestão: é a capacidade da propriedade agropecuária/florestal de regular e controlar suas ações com o ambiente externo. Um exemplo de baixa capacidade de autogestão é a necessidade de aquisição de fertilizantes do solo de um agroecossistema; - Estabilidade: é capacidade da propriedade agropecuária/florestal manter um mesmo ritmo de produção ao longo prazo, visando sua constante produtividade; - Resiliência: é a capacidade da propriedade agropecuária/florestal retornar ao estado de equilíbrio após a ocorrência de perturbações graves, mantendo seu potencial produtivo. Um exemplo é manter o equilíbrio econômico determinada unidade produtiva após uma baixa de preço repentino um produto relevante; - Confiabilidade: refere-se da capacidade do sistema de manter sua produtividade ou benefícios esperados em níveis próximos ao normal, mantendo o equilíbrio sem grandes variações na produtividade, mesmo que o ambiente sofra perturbações.

Verificados os atributos, segue-se para aplicação da metodologia MESMIS através do seu passo-apasso. Assim, por meio dos atributos constituídos são elencadas as potencialidades e limitações, gerando os pontos críticos do sistema, bem como, o enquadramento dos indicadores em cada dimensão da sustentabilidade, logo após serão estabelecidos os critérios de diagnóstico para mensurar os indicadores, 
realizados estas etapas é realizado sua mensuração e monitoramento e por fim, integralizado os resultados para as conclusões e recomendações necessárias. Ver Figura 4.

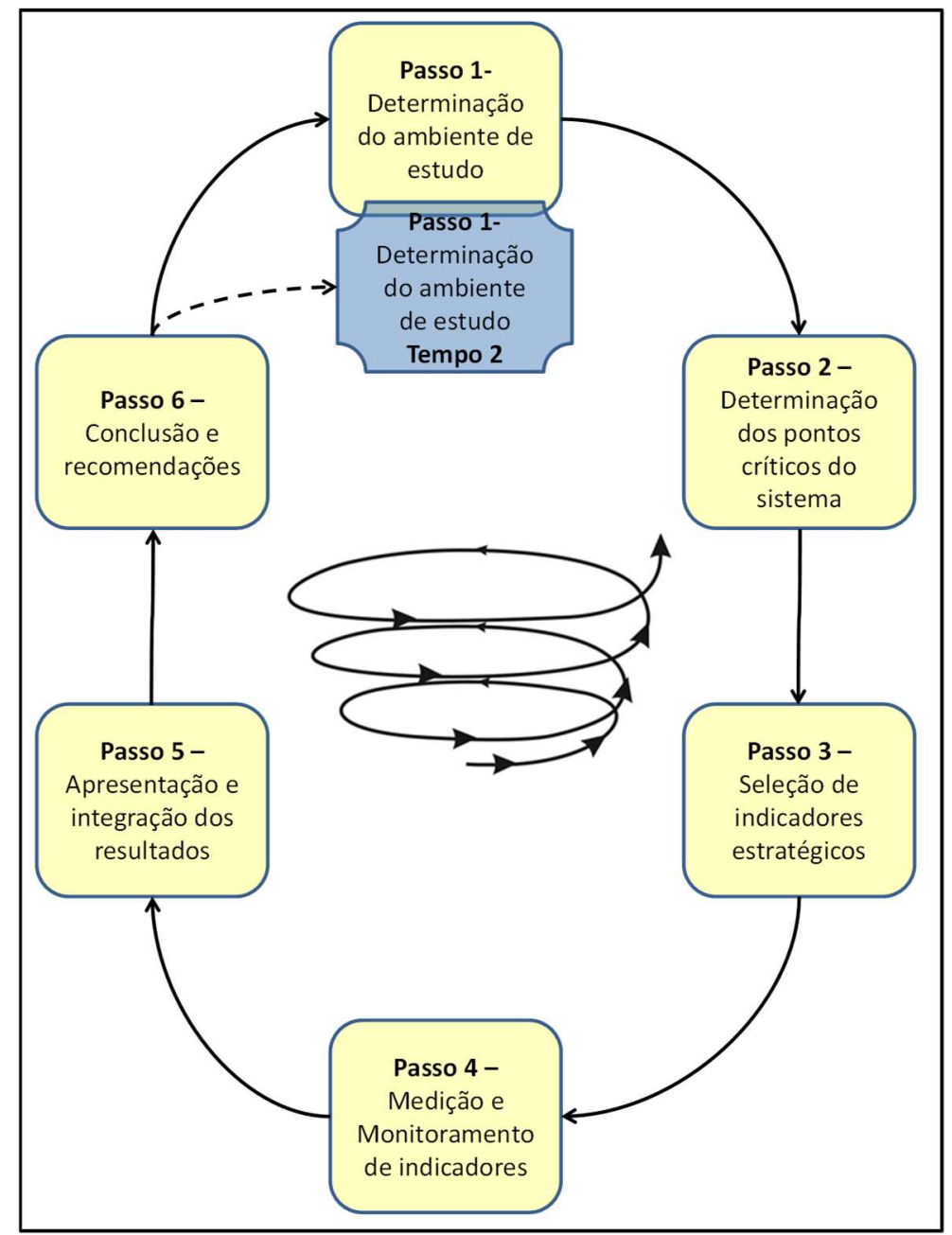

Figura 4: Ciclo de avaliação da sustentabilidade proposto pelo MESMIS. Fonte: Elaborado a partir de Masera et al. (1999).

De maneira geral os seis passos do ciclo de avaliação da sustentabilidade da metodologia MESMIS vai desde a identificação dos sistemas de produção até as propostas alternativas para fortalecer a sustentabilidade, em que segue a lógica do constante monitoramento dos pontos críticos a fim de um melhor entendimento do agroecossistema em estudo com fins na sustentabilidade

Desse modo, o MESMIS entende a sustentabilidade como um processo que se constrói a partir de uma visão local coletiva, segundo a cooperação de todos os membros de uma sociedade (ASTIER et al., 2008). Nesse sentido o capital social pode vir a somar e impulsionar da sustentabilidade como uma alternativa para o fortalecimento da caprinocultura leiteira e consequentemente, do desenvolvimento local.

\section{RESULTADOS E DISCUSSÃO}

\section{Determinação do ambiente de estudo}

Para Perdigão et al. (2016), destaca-se duas regiões no Brasil com estímulo à produção do leite de cabra, o Nordeste e o Sudeste. Na região Nordeste existe incentivo para a produção por parte dos governos federal e estaduais através do Programa de Aquisição de Alimentos (PAA), no qual o governo compra o leite 
caprino objetivando fortalecer agricultores familiares e, ao mesmo tempo, alimenta uma faixa da população em risco alimentar com tal produto. Na região Sudeste, segunda maior região produtora de leite no país, o incentivo para a produção é um nicho de mercado consumidor especial, que busca produtos diferenciados de valor agregado, "gourmet", ou mesmo nutracêuticos. Ver Figura 5.

Segundo o IBGE no seu Censo Agropecuário de 2017, o Estado da Paraíba ocupa o primeiro lugar na produção de leite caprino no Brasil, com 21\% do total produzido em todo país no ano de 2017 e a região do Cariri Ocidental é responsável por 71\% de toda produção no estado (IBGE, 2017). Por este motivo, justificase delimitar o objeto de estudo a esta microrregião, por sua representatividade produtiva e, consequentemente econômica para a Paraíba. Conforme Figura 6.

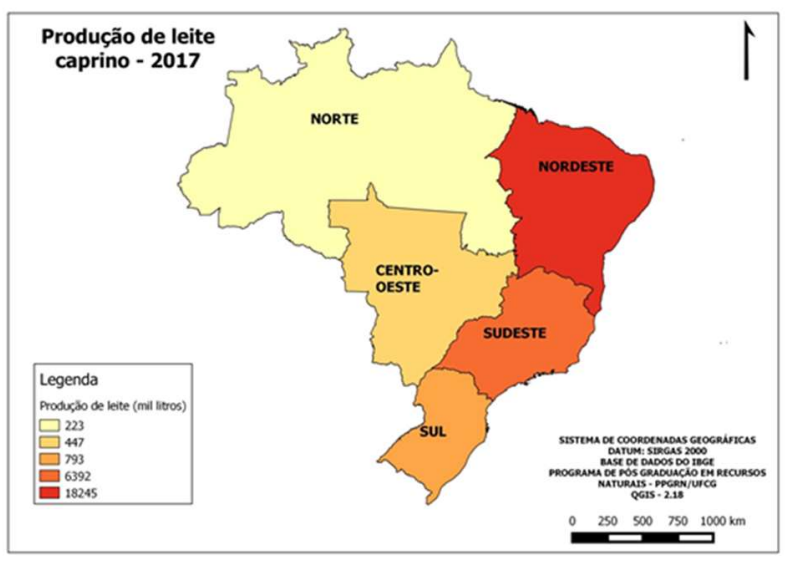

Figura 5: Mapa da distribuição quantitativa da produção de leite caprino por região brasileira (2017).

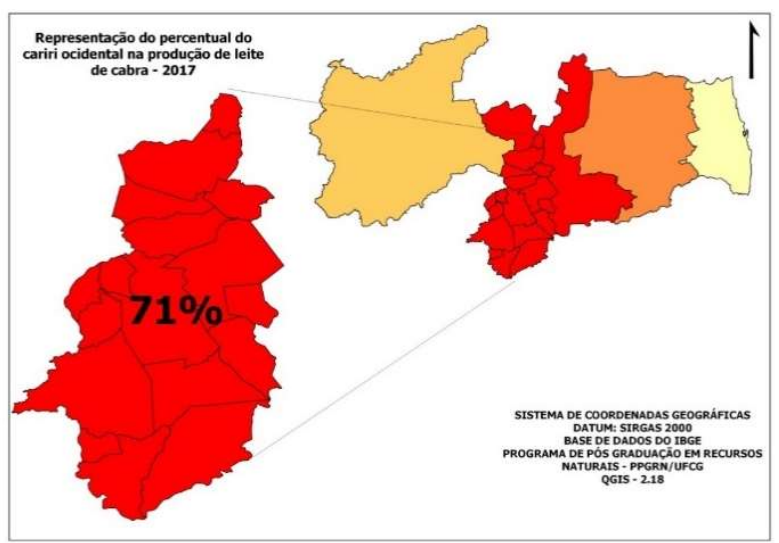

Figura 6: Representação da produção de leite caprino do Cariri Ocidental em relação à Mesorregião da Borborema - Paraíba (2017).

Assim, no ano de 2017 produziu quase 5,5 milhões de litros, o equivalente a $21 \%$, da produção nacional, em segundo lugar a Bahia com 5,3 milhões, mas com um rebanho 5 (cinco) vezes maior do que o da Paraíba (IBGE, 2019). O que demostra que a qualidade do rebanho paraibano em termos de produtividade e merece destaque. Abaixo segue a distribuição

Tabela 1: Quantidade produzida de leite de cabra pelos municípios do Cariri Ocidental da Paraíba em 2017.

\begin{tabular}{|c|c|c|c|}
\hline Município & Litros de leite & Intervalos - litros de leite & \% em relação ao Cariri Ocidental \\
\hline Monteiro (PB) & 684.000 & \multirow{4}{*}{ Acima de 270.000} & \multirow{4}{*}{$62,5 \%$} \\
\hline Amparo (PB) & 683.000 & & \\
\hline Taperoá (PB) & 543.000 & & \\
\hline Sumé (PB) & 507.000 & & \\
\hline Parari (PB) & 242.000 & \multirow{4}{*}{ Acima de $180.000 \leq 270.000$} & \multirow{4}{*}{$21 \%$} \\
\hline Prata (PB) & 209.000 & & \\
\hline São Sebastião do Umbuzeiro (PB) & 182.000 & & \\
\hline Zabelê (PB) & 182.000 & & \\
\hline Coxixola (PB) & 145.000 & \multirow{4}{*}{ Acima de $90.000 \leq 180.000$} & \multirow{4}{*}{$12 \%$} \\
\hline Livramento (PB) & 116.000 & & \\
\hline Ouro Velho (PB) & 100.000 & & \\
\hline Camalau & 93.000 & & \\
\hline São José dos Cordeiros (PB) & 65.000 & \multirow{5}{*}{$0-90.000$} & \multirow{5}{*}{$4,5 \%$} \\
\hline São João do Tigre (PB) & 58.000 & & \\
\hline Serra Branca (PB) & 42.000 & & \\
\hline Congo (PB) & 11.000 & & \\
\hline Assunção & 0.000 & & \\
\hline
\end{tabular}


A tabela 1 aglomera os municípios do cariri ocidental de acordo com sua respectiva produção de leite, estabelecendo 04 (quatro) intervalos em ordem decrescente variando de 0.00 a 270.00 litros de leite com intervalo entre as classes de 90.000. Observa-se que o intervalo em que se encontram os municípios de Monteiro, Amparo, Taperoá e Sumé representa mais da metade da produção de leite paraibana com 63\%, por outro lado, o intervalo em que se concentram os municípios de São José dos Cordeiros, São João do Tigre, Serra Branca, Congo e Assunção, são os menos expressivos dessa microrregião, totalizando apenas 5\% da produção total de leite.

\section{Determinação dos pontos críticos do sistema}

Pontos críticos são aspectos econômicos, técnicos, sociais e ambientais que podem fortalecer (positivo) ou enfraquecer (negativo) os atributos produtividade, estabilidade, confiança, resiliência, equidade, adaptabilidade e autossuficiência. Expõe as fragilidades, vulnerabilidades e robustez do sistema.

Uma forma de obtenção dos pontos críticos é por meio da análise SWOT (Strengths, Weaknesses, Opportunities e Threats) ou também conhecido como análise FOFA (Forças, Fraquezas, Oportunidades e Ameaças), em que as variáveis internas (forças e fraquezas) são controláveis pelo agricultor, ou seja, pode ter domínio sobre elas. Já as vaiáveis externas (Oportunidades e Ameaças), são incontroláveis, logo, o agricultor não poderá intervir sobre elas, foge do seu domínio. Por exemplo, concorrência, leis regulamentadoras, preço de mercado, entre outros aspectos. Assim, cada ponto crítico se converterá em indicador e poderá ser relacionado a um ou mais atributos.

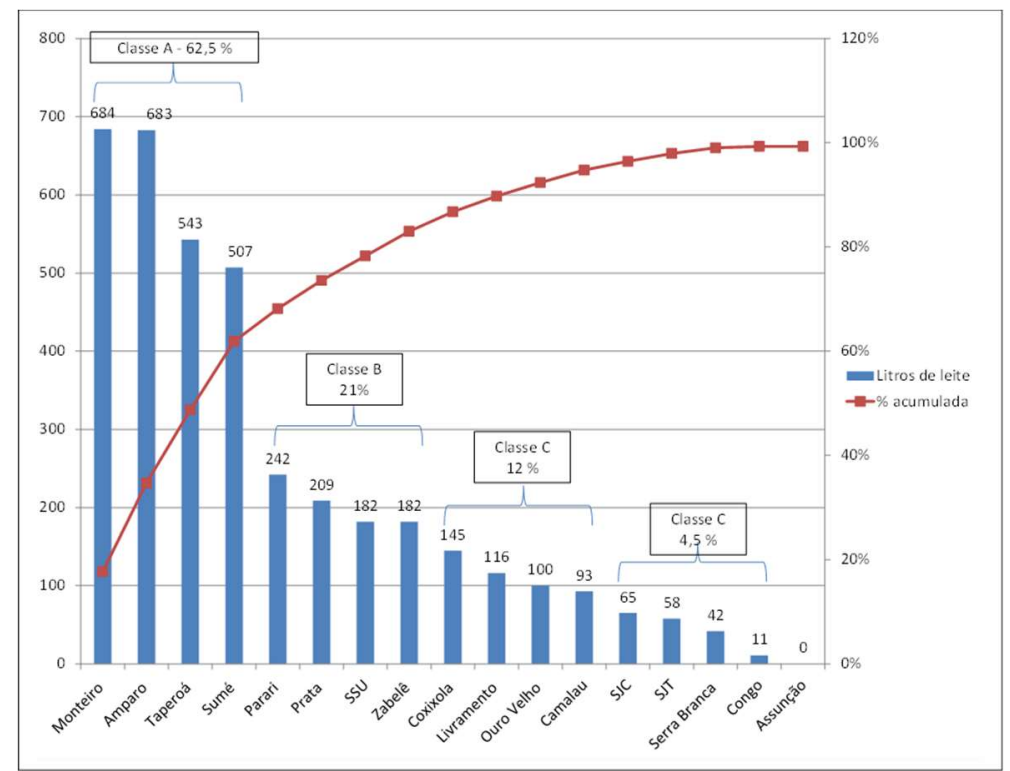

Figura 7: Classificação dos municípios do cariri ocidental - mil/litros de leite 2017

Partindo dessa dinâmica, foi necessário visitar alguns municípios para avaliar os pontos críticos do sistema, cada vez que um município era visitado novos pontos críticos (positivos e negativos) eram percebidos ou fortalecidos os já evidenciados. Dessa forma, foi necessário estratificar em 04 (quatro) classes diferentes os municípios 17 (dezessete) municípios do cariri ocidental de acordo com suas respectivas produção de leite como forma de viabilizar a pesquisa no tocante a coleta dos dados e sua operacionalização, 
em que apenas os municípios mais representativos de cada classe foram contemplados, foram eles: classe $\mathrm{A}$ (Monteiro), classe B (Parari), classe C (Coxixola) e classe D (São José dos Cordeiros - SJC).

De acordo como os pontos críticos do sistema, verifica-se que independente da classe em que o município esteja classificado, as dificuldades, desafios e as potencialidades são muito parecidas, o que demostra um setor bastante homogêneo e previsível. Talvez por estarem na mesma região semiárida, próximos geograficamente e pertencentes ao mesmo estado federativo, em que as políticas públicas são praticamente as mesmas.

Neste sentido, verificou-se que o capital social não pode ser esquecido quando se trata de associações de agricultores, em que as relações sociais entre os indivíduos deveriam ser contempladas, não se limitando apenas aos atributos propostos pela metodologia MESMIS, sendo assim, se limitar apenas aos aspectos ecológicos, de produtividade, ao capital físico (materiais) e capital humano, para que uma associação funcione satisfatoriamente não seria o suficiente. Faltava algo que desse a liga, um complemento que pudesse unir as várias partes do sistema e enfatizasse de maneira peculiar as relações humanas. Nesse viés, surge a necessidade de incluir o capital social como atributo para suprir essa deficiência metodológica.

Sendo assim, ao analisar a sustentabilidade do agroecossistema da caprinocultura leiteira do cariri paraibano, percebeu-se após as visitas nas propriedades rurais que o atributo capital social é de suma importância para o fortalecimento da cadeia produtiva leiteira, onde os pequenos produtores se reúnem em associações rurais a fim de fortalecer ainda mais suas relações sociais através da confiança e solidariedade, atendendo a demanda e os critérios estabelecidos pelas cooperativas que beneficiam o leite.

\section{Seleção dos indicadores de sustentabilidade}

A seleção dos indicadores foi realizada de forma participativa em dois momentos; No primeiro, foi realizado um levantamento dos pontos críticos com os produtores e técnicos (extensionistas rurais), com base nas informações coletadas nas entrevistas e questionários. Logo após, os pontos críticos foram transformados em indicadores e separados por suas características intrínsecas dentro dos diferentes processos: ambientais, operacionais, econômicos e sociais que limitam ou fortalecem a capacidade de os sistemas serem sustentáveis ao longo do tempo. No segundo momento, foram apresentados nas reuniões das associações dos produtores de leite e identificados de forma participativa aqueles indicadores estratégicos (Quadro 1).

Quadro 1: Indicadores para avaliação da sustentabilidade da caprinocultura leiteira na Paraíba - PB.

\begin{tabular}{|c|c|c|c|}
\hline Atributos & Critério de diagnóstico & Indicadores & Áreas de avaliação \\
\hline \multirow[t]{5}{*}{ Produtividade } & \multirow{3}{*}{ Rentabilidade } & 1. Renda oriunda da caprinocultura & Econômica/Social \\
\hline & & 2. Atraso no pagamento & Econômica \\
\hline & & 3. Renda de atividades agrícolas & Econômica/Social \\
\hline & \multirow{2}{*}{ Eficiência produtiva } & 4. Cota governamental & Econômica \\
\hline & & 5. Potencial genético dos animais & Econômica \\
\hline \multirow[t]{3}{*}{$\begin{array}{l}\text { Estabilidade, Resiliência, } \\
\text { Confiabilidade }\end{array}$} & \multirow[t]{2}{*}{ Diversidade } & $\begin{array}{l}\begin{array}{l}\text { 6. Diversidade de atividades produtivas } \\
\text { exploradas }\end{array} \\
\end{array}$ & Econômica \\
\hline & & $\begin{array}{l}\text { 7. Diversidade de espécies de animais } \\
\text { exploradas }\end{array}$ & Econômica \\
\hline & Conservação dos recursos & 8. Degradação física do solo - ausência de & Ambiental \\
\hline
\end{tabular}




\begin{tabular}{|c|c|c|c|}
\hline & naturais & rotação de pastagem/capineira & \\
\hline & & 9. Plantio para alimentação animal & Ambiental \\
\hline & & 10. Disposição dos resíduos (dejeto animal) & Ambiental \\
\hline & & 11. Disponibilidade de água & Ambiental \\
\hline \multirow{5}{*}{ Adaptabilidade } & \multirow[t]{2}{*}{ Capacidade de inovação } & $\begin{array}{l}\text { 12. Adoção de novas tecnologias - ordenhas } \\
\text { mecânica }\end{array}$ & Social \\
\hline & & 13. Processo/Produto & Ambiental/Econômica \\
\hline & \multirow{2}{*}{ Aprendizado } & 13. Aprimoramento das técnicas de manejo & Social \\
\hline & & 14. Produção de forragem & Ambiental/Econômica \\
\hline & Capacidade de competição & 15. Canais de comercialização & Econômica \\
\hline \multirow{5}{*}{ Equidade } & Trabalho familiar & 16. Distribuição do trabalho familiar & Social \\
\hline & Mão de obra & 17. Disponibilidade de mão de obra solidária & Social \\
\hline & Compra governamental & 18. Percepção do preço comercializado & Econômica \\
\hline & Satisfação & $\begin{array}{l}\text { 19. Satisfação de moradia do agricultor e seu } \\
\text { cônjuge }\end{array}$ & Social \\
\hline & Qualidade de vida & 20. Qualidade de vida & Social \\
\hline \multirow[t]{5}{*}{ Autogestão } & Participação & $\begin{array}{l}\text { 21. Participação efetiva nas decisões na } \\
\text { associação/cooperativa }\end{array}$ & Social \\
\hline & Comercialização & 22. Insuficiente mercado comprador & Social \\
\hline & Segurança alimentar & 23. Disponibilidade de forragem & Econômica \\
\hline & \multirow[t]{2}{*}{ Organização } & $\begin{array}{l}\text { 24. Organização estratégica entre os } \\
\text { produtores }\end{array}$ & Social \\
\hline & & $\begin{array}{l}\text { 25. Eventos culturais em alusão a } \\
\text { caprinovinocultura }\end{array}$ & Social \\
\hline \multirow{18}{*}{ Capital Social } & \multirow{3}{*}{ Grupos e Redes } & 26. Participação em grupo social & Social \\
\hline & & 27. Assistência e apoio técnico & Social \\
\hline & & 28. Quantidades de reuniões & Social \\
\hline & \multirow[t]{3}{*}{ Confiança e Solidariedade } & 29. Nível de confiança & Social \\
\hline & & 30. Transferência de tecnologias sociais & Social \\
\hline & & 31. Transação financeira & Social \\
\hline & \multirow[t]{3}{*}{ Ação coletiva e cooperação } & 32 Atividades voluntárias & Social \\
\hline & & $\begin{array}{l}\text { 33. Participação nas reuniões da } \\
\text { associação/cooperativa }\end{array}$ & Social \\
\hline & & 34. Ajuda mútua no manejo & Social \\
\hline & \multirow[t]{3}{*}{ Informação e Comunicação } & 35. Informações do governo e mercados & Social \\
\hline & & 36. Capacidade de resolver conflitos & Social \\
\hline & & 37. Meios de comunicação estabelecidos & Social \\
\hline & \multirow[t]{3}{*}{ Coesão e Inclusão Social } & 38. Relação de enfraquecimento social & Social \\
\hline & & 39. Nível de conflito & Social \\
\hline & & 40. Grau de respeito à opinião & Social \\
\hline & \multirow{3}{*}{$\begin{array}{l}\text { Autoridade ou Capacitação } \\
\text { e Ação Politica }\end{array}$} & 41. Envolvimento na tomada de decisão & Social \\
\hline & & 42. Acessibilidade aos políticos & Social \\
\hline & & 43. Atendimento do governo as demandas & Social \\
\hline
\end{tabular}

A matriz de avaliação da sustentabilidade proposta pode ser entendida como uma ferramenta de apoio à decisão que deve ser monitorada constantemente no intuito de informar a situação da sustentabilidade da caprinocultura leiteira do semiárido, proporcionando assim uma atividade produtiva mais competitiva e rentável para o homem do campo.

Ainda sobre a matriz de avaliação proposta, verifica-se uma quantidade considerada dos indicadores de sustentabilidade voltados para o atributo capital social, o que antes eram negligenciados, necessitando de uma maior atenção por parte dos formuladores dos indicadores estratégicos. Assim, estudar agroecossistemas de base familiar sem levar em consideração a relação social entre a comunidade, os produtores e o setor produtivo analisado, neste caso, a caprinocultura leiteira, pode não retratar a realidade do sistema em estudo e ter uma concepção errônea sobre a sustentabilidade.

Desse modo, a partir da inclusão do atributo capital social dentro da metodologia MESMIS, tem-se a premissa que quanto mais presentes forem à incorporação dos princípios de confiança, engajamento cívico 
e cooperação no processo de avaliação da sustentabilidade da caprinovinocultura, mais fidedigna serão as informações que viabilizarão a atividade pecuária de forma sustentável.

\section{Framework para avaliação da caprinocultura leiteira}

A partir da busca pela sustentabilidade da atividade leiteira da caprinocultura, a adaptação do método MESMIS através do incremento capital social, poderá identificar as potencialidades e vulnerabilidades do sistema e incorporar as práticas sustentáveis adequadas ao contexto local

Os critérios de diagnóstico para analisar o atributo capital social foram escolhidas algumas informações básicas. De acordo com Grootaert et al. (2003), são três dimensões úteis para medir o capital social de maneira relevante para as políticas públicas, são eles: grupos e redes; confiança e solidariedade; ação coletiva e cooperação; Informação e comunicação, coesão e inclusão social e; autoridade ou capacitação. Sendo assim, foram adotadas as seis dimensões como critérios de diagnóstico para avaliar o atributo capital social, em que a partir da criação dos indicadores de sustentabilidade voltado para esta temática será possível ter uma visão mais ampla e real do agroecossistema estudado. A figura a seguir mostra como se configura o modelo de avaliação proposto para a caprinocultura leiteira. Veja a figura 8.

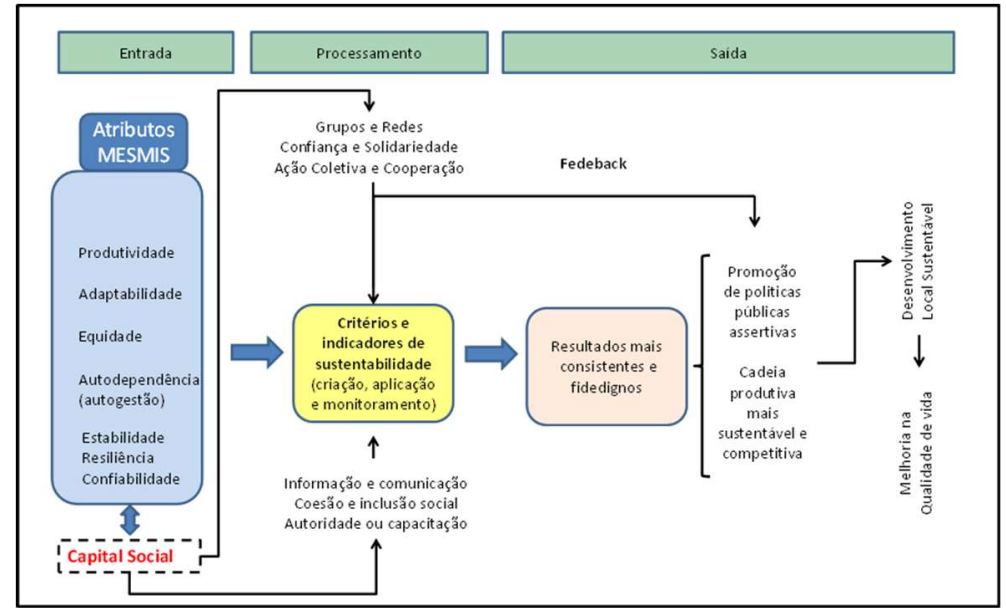

Figura 8: Framework de avaliação da sustentabilidade da caprinovinocultura leiteira.

A Figura 8 propõe um modelo de avaliação da sustentabilidade para caprinocultura leiteira com base na inclusão do atributo capital social na metodologia MESMIS, onde tem-se sua relevância a partir dos dados empíricos coletados na forma de entrevistas não estruturadas e diálogos informais junto aos produtores rurais.

Em linhas gerais, o framework proposto para de avaliação da sustentabilidade da caprinovinocultura leiteira, divide-se na inclusão do atributo capital social, a criação de critérios/parâmetros e indicadores em que a inter-relação desse conjunto de partes resulta no desenvolvimento local e na melhoria da qualidade de vida do homem do campo e sua família.

Assim, este modelo foi criado a partir da lógica de sistemas complexos, interligando um conjunto de partes para entender o todo e sua autorregulação. Portanto, não se pode estudar a sustentabilidade de qualquer atividade produtiva de base familiar sem entender a totalidade das partes que a constitui, inclusive 
as relações sócias entre os produtores e a comunidade.

Desde modo, uma característica fundamental dos sistemas complexos é a emergência (evento ou comportamento inesperado), fenômeno que surge da interação entre seus componentes e partes. Esta emergência é justamente a inclusão do termo capital social como atributo complementar na metodologia MESMIS. Assim, reforça o valor do capital social nas relações sistêmicas de sustentabilidade.

De acordo com Masera et al. (1999), os criadores do método MEMIS, definem como uma ferramenta que colabora na avaliação da sustentabilidade de manejo de recursos naturais, com ênfase no contexto da agricultura familiar e no âmbito local, buscando entender os fatores limitantes e as possibilidades para a sustentabilidade dos sistemas de manejo que surgem da interseção de processos ambientais com o âmbito social e econômico.

Por fim, tem-se como aprendizado que o modelo proposto para avaliação da sustentabilidade da caprinocultura leiteira é dinâmico e necessita do feedback constante para que se necessário, novos gargalos sejam identificados e gerados outros indicadores estratégicos, favorecendo políticas públicas mais assertivas e eficazes para a atividade produtiva, bem como, seu fortalecimento e sua maior competitividade. Resultando assim, no almejado desenvolvimento sustentável da cadeia produtiva.

\section{CONCLUSÕES}

Assim, o presente estudo, foi aplicado o método MESMIS até a sua terceira etapa, que trata sobre a construção dos indicadores estratégicos de sustentabilidade, onde de maneira participativa (produtores, extensionistas e pesquisadores); constatou-se que, durante essa fase, foi possível identificar gargalos, os pontos críticos e a partir deles criar os indicadores do sistema.

Neste sentido, a partir do contato do pesquisador com os produtores de leite e sua família foi criado um laço de confiança mútuo, o que favoreceu identificar uma lacuna na metodologia MESMIS no tocante às relações sociais. Pois, foi verificado que é importante incluir mais um atributo de cunho social além dos já existentes na metodologia MESMIS, com o objetivo de aprimorar ainda mais o método e trazer resultados mais consistentes e fidedignos. Sendo assim, devido à flexibilidade do método MESMIS foi possível criar o conjunto de indicadores de sustentabilidade voltados para a caprinocultura leiteira no cariri ocidental paraibano e adaptado para a realidade local, mas que o acompanhamento proposto ao sistema possibilitará a discussão dos indicadores mais apropriados e a incorporação de outros, ou seja, suas adaptações e a busca pela melhoria contínua torna a metodologia dinâmica e mais precisa.

Portanto, o atributo capital social tem que ser lembrado diante a sua relevância no contexto da agricultura familiar, pois não se podem estudar atividades produtivas que envolvam associações ou cooperativas sem entender os vínculos e interações entre os atores sociais. Por fim, a matriz de indicadores levou a criação de um framework da caprinocultura leiteira, em que o capital social é um fator crítico de sucesso para o desenvolvimento desse importante agroecossistema para a economia local. 


\section{REFERÊNCIAS}

ANDRADE, R. L. P.. Consequências positivas das barreiras não-tarifarias no comércio internacional de produtos do agronegócio: o caso da carne bovina. Tese (Doutorado em Desenvolvimento, Agricultura e Sociedade) - Universidade Federal do Rio de Janeiro, Rio de Janeiro, 2007.

ASTIER, M.; MASERA, O.; GALVÁN-MIYOSHI, Y.. Evaluación de Sustentabilidad: Un enfoque dinámico $y$ multidimensional. Fundación Instituto de Agricultura Ecológica y Sustentable, 2008.

BECATTINI, G.. Del distrito industrial marshalliano a la "teoría del distrito" contemporánea. Una breve reconstrucción crítica. In: Investigaciones Regionales. Madrid: Asociación Española de Ciencia Regional, 2002. p.932.

COLEMAN, J. S.. Social Capital in the Creation of Human Capital. American Journal of Sociology, v.94, p.95-120, 1988.

GROOTAERT, C.; NARAYAN, D.; JONES, V. N.; WOOLCOCK, M.. Questionário Integrado para Medir Capital Social (QIMCS). Grupo Temático sobre Capital Social. Washington: World Bank, 2003.

IBGE. Instituto Brasileiro de Geografia e Estatística. Pesquisa pecuária municipal. Sidra: sistema IBGE de recuperação automática. Rio de Janeiro: IBGE, 2019

IBGE. Instituto Brasileiro de Geografia e Estatística. Censo Agropecuário 2017. Sidra: sistema IBGE de recuperação automática. Rio de Janeiro: IBGE, 2017

MASERA, O.; ASTIER, M.; LÓPEZ-RIDAURA, S..

Sustentabilidad Y Manejo de Recursos Naturales: el marco de evaluación MESMIS. Ciudad do México: Mundi-Prensa, 1999.

OLIVEIRA, L. S.. Características e sustentabilidade de sistemas de produção de caprinos leiteiros no Nordeste do Brasil. Tese (Doutorado em Zootecnia) - Universidade Estadual Paulista, Jaboticabal, 2020.

PUTNAM, R. D.. Comunidade e Democracia: a experiência da Itália moderna. 2 ed. Rio de Janeiro: FGV, 2002.

VERGARA, S. C.. Projetos e relatórios de pesquisa em administração. 8 ed. São Paulo: Atlas, 2007.

VERONA, L. A. F.. A real sustentabilidade dos modelos de produção da agricultura: Indicadores de sustentabilidade na agricultura. Horticultura Brasileira, v.28, n.2, p.52-66, 2010.

A CBPC - Companhia Brasileira de Produção Científica (CNPJ: 11.221.422/0001-03) detém os direitos materiais desta publicação. Os direitos referem-se à publicação do trabalho em qualquer parte do mundo, incluindo os direitos às renovaç̃̃es, expansões e disseminações da contribuiç̃o, bem como outros direitos subsidiários. Todos os trabalhos publicados eletronicamente poderão posteriormente ser publicados em coletâneas impressas sob coordenação da Sustenere Publishing, da Companhia Brasileira de Produção Científica e seus parceiros autorizados. Os (as) autores (as) preservam os direitos autorais, mas não têm permissão para a publicação da contribuição em outro meio, impresso ou digital, em português ou em tradução. 